\title{
Micropropagation of Solanum lycopersicum L. using chemical free formulated organic plant growth media
}

\author{
Suman Kashyap ${ }^{* 1,2}$, Shreyaa $\mathbf{S}^{1}$, Akshaya Suresh ${ }^{1}$ \& Seema Tharannum ${ }^{1}$ \\ ${ }^{1}$ Department of Biotechnology, Jain Deemed-to-be University, Bengaluru 560 069, India \\ ${ }^{2}$ Department of Biotechnology, PES University, Bengaluru 560 085, India
}

*Email: sumkash925@gmail.com

\section{OPEN ACCESS}

\section{ARTICLE HISTORY}

Received: 23 June 2021

Accepted: 1 November 2021

Available online

Version 1.0 (Early Access): 30 November 2021 Version 2.0:01 January 2022

\section{Check for updates}

\section{Additional information}

Peer review: Publisher thanks Sectional Editor and the other anonymous reviewers for their contribution to the peer review of this work.

Reprints \& permissions information is available at https://horizonepublishing.com/ journals/index.php/PST/open_access_policy

Publisher's Note: Horizon e-Publishing Group remains neutral with regard to jurisdictional claims in published maps and institutional affiliations.

Indexing: Plant Science Today, published by Horizon e-Publishing Group, is covered by Scopus, Web of Science, BIOSIS Previews, Clarivate Analytics, etc. See https:// horizonepublishing.com/journals/index.php/ PST/indexing_abstracting

Copyright: @ The Author(s). This is an openaccess article distributed under the terms of the Creative Commons Attribution License, which permits unrestricted use, distribution and reproduction in any medium, provided the original author and source are credited (https://creativecommons.org/licenses/ by/4.0/)

\section{CITE THIS ARTICLE}

Kashyap S, Shreyaa S, Suresh A, Tharannum S. Micropropagation of Solanum lycopersicum L. using chemical free formulated organic plant growth media. Plant Science Today. 2022;9(1):132-136. https://doi.org/10.14719/ pst.1348

\begin{abstract}
Micropropagation is a useful biotechnology technique for the generation of a large number of clonal plants of many economically important species in a short period. An effective protocol was developed for in vitro micropropagation of Solanum lycopersicum L. (tomato) using chemical-free organic vermicompost extract medium. This experiment aims to expose the advancement in plant tissue culture technique by using synthetic Murashige and Skoog (MS) medium and chemical-free organic vermicompost (30\%) extract along with $4 \%$ coelomic fluid (obtained from the earthworms Eudrilus eugeniae) as a growth medium for in vitro studies. The response of roots, leaves, shoots, and nodes in both synthetic MS medium and chemical-free organic vermicompost extract medium was compared. Statistically significant differences for the number of roots $(P=0.011)$, leaves $(P=0.012)$, and nodes $(P=0.001)$ between the two media were reported. Both media showed the same shoot induction where no significant differences $(P>0.05)$ were found. A $100 \%$ plant survival rate on the chemical-free organic vermicompost extract medium was registered. A difference between the growth rate of the two different media was detected. The antimicrobial activity of vermicompost and coelomic fluid minimized the contamination level and subculturing. This study revealed that chemical-free organic vermicompost extract media is more economical and constitutes a better prospect than the MS medium for in vitro propagation of tomato.
\end{abstract}

\section{Keywords \\ coelomic fluid, economical, Eudrilus eugeniae, MS medium, tomato, vermicompost}

\section{Introduction}

Solanum lycopersicum L. (tomato) is a perennial crop that belongs to the Solanaceae family and is marked as a significant fruit that stands second in consumption because of its higher nutritive values (1). It is native to South America and is primarily distributed in temperate regions (2). Tomato is considered a major dietary source as it contains fiber, essential vitamins like A and C, antioxidants in substantial amounts and is also found to be free of cholesterol (3). Lycopene is a powerful antioxidant that is present in tomatoes and has been validated for its beneficial effects on various types of cancers (4), cardiovascular diseases and osteoporosis (5). Due to the commercial value of the crop and the fact that tomato is widely grown in developed regions, in vitro regeneration of tomatoes has been a subject of interest. Since tomatoes are used in canned, frozen, and preserved foods, they are considered to be economically important and hence have been chosen for 
our in vitro propagation study (6). Micropropagation is a widely used plant biotechnology technique that allows the production of a large number of clonal plants that are disease and pathogen-free. It is also a technical link in the generation of transgenic plants and otherwise somatically bred plants (7). Cultivation of Arka Vikas tomato variety is preferred to India because of its special adaptation and characteristic features like higher yields and direct regeneration with growth hormones (8). Several researchers (9, 10) reported earlier callus induction and micropropagation of cultivated tomato. Multiple shoots were induced using explants viz cotyledons, hypocotyl and leaf segments and plant media supplemented with BAP, Kinetin, TDZ and Zeatin alone and in combinations with IAA $(11,12)$ and the outcomes of direct regeneration on using hormones have been investigated (13). Auxin hormones like IAA are involved in cell elongation and cytokinins such as Kinetin and BAP promote cell division and help in stem elongation, contributing for plant growth and development (14). The success in tomato regeneration response depends on the genotype, explant type and growth hormones used in the culture medium (15). The conventional method of vegetative propagation has been a time-consuming and energy-expensive process. Hence, the present study on micropropagation of tomato using organic plant tissue culture medium serves as an easier and environmentally friendly method for germplasm conservation. Research has been carried out to examine the effect of earthworm castings on plant growth $(16,17)$. Vermicompost media has been used in the present study as it is found to be rich in macronutrients, micronutrients, vitamins, enzymes like chitinase etc., that disintegrate matter even after ejection by earthworms and they also contain hormones (18). Coelomic fluid, also known as vermiwash, was added to the vermicompost media as it helps in increased plant growth and also helps reduce contamination in the tissue culture bottles because of its antimicrobial property (19). The objective of the current study is to develop an economical, chemical-free and organic vermicompost extract medium along with coelomic fluid for in vitro micropropagation of S. lycopersicum suitable for large-scale manufacturing of tomato in the future.

\section{Materials and Methods}

\section{Plant material and Preparation of media}

Plant material used- Arka Vikas tomato cultivars were purchased from the local market in Bengaluru and the seeds were separated and used as the explant.

MS medium was purchased from Sigma chemicals, was used as the synthetic control medium. Eudrilus euginae (earthworm), and vermicompost were procured from Vermibin at PES University, Bengaluru.

Two media culture were used for culturing seed explants of S. lycopersicum. Murashige and Skoog (MS) medium (27) (Sigma Chemicals), pH 5.6-5.8, supplemented with $30 \%$ sucrose and $0.000003 \mathrm{~kg} / \mathrm{L}$ BAP and solidified with $0.009 \mathrm{~kg} / \mathrm{L}$ plant grade agar was used as control.
Plant, vegetable organic waste mix and cow dung slurry were used as the raw materials for the production of vermicompost by the earthworms- Eudrilus eugeniae. Vermicompost $(30 \%)$ obtained was suspended in sterile distilled water and was agitated for $8 \mathrm{hrs}$. The aqueous extract (filtrate) obtained after 24 hrs was used for media preparation. $\mathrm{pH}$ was adjusted to 5.8 and supplemented with $0.009 \mathrm{~kg} / \mathrm{L}$ agar (25). Additionally, coelomic fluid was extracted from earthworms- Eudrilus eugeniae, using a chemical method (5\% chilled ethanol and $2.5 \mathrm{mg} / \mathrm{ml}$ of EDTA). Thick straw-colored coelomic fluid obtained was filter sterilized and was used as a supplement in the sterile vermicompost extract media.

Control MS medium and organic vermicompost extract medium were sterilized at $15 \mathrm{PSI}$ and $121{ }^{\circ} \mathrm{C}$. After sterilization, MS media bottles were supplemented with $3 \mathrm{mg} / \mathrm{L}$ BAP and organic vermicompost media bottles were supplemented with filter-sterilized $4 \%$ coelomic fluid.

Seeds of S. lycopersicum were separated from tomatoes that were obtained from the local market and were used as the explant. The seeds were treated with $2 \%$ Tween 20 for $5 \mathrm{~min}$, 5\% Sodium hypochlorite solution for 10 min finally with $70 \%$ ethanol for 2 min under aseptic conditions. Seeds were then washed thoroughly several times with sterile distilled water. Sterile tomato seeds were inoculated under aseptic conditions on both the MS media and vermicompost media bottle jars. Culture bottles were incubated for 16 hrs of fluorescent white light (day) photoperiod and $8 \mathrm{hrs}$ of darkness at a temperature of $25^{\circ} \mathrm{C}$.

\section{Data Analysis}

Three biological replicates, with three seed explants each were analyzed for the growth response of roots, leaves, shoots and nodes in both MS medium and chemical-free vermicompost extract medium. The mean values were compared statistically by the Student's t-test using SigmaStat 4.0 software.

\section{Results and Discussion}

An economically effective protocol was developed for tissue culture studies on tomatoes, which could also be utilized for the large-scale micropropagation of tomatoes. The seeds of S. lycopersicum cultured on MS medium supplemented with $0.000003 \mathrm{~kg} / \mathrm{L}$ BAP resulted in callus formation. BAP is one of the most frequently used cytokinin as it is more stable, cheaper, easily obtained than other growth hormones and promotes other hormonal syntheses essential for plant growth (20). Tomato seed explants on chemical-free organic vermicompost extract media supplemented with $0.0002 \mathrm{~kg} / \mathrm{L}$ coelomic fluid resulted in regeneration directly from the seed explants- tiny shoots germinated on the third day of inoculation. 100\% germination was observed in both MS and vermicompost media after 3 days. Researchers have reported $0.000003 \mathrm{~kg} / \mathrm{L} \mathrm{BAP}$ as an optimal concentration of growth hormones for tomato regeneration and maximum multiplication of shoots $(21,22)$. Adventitious shoot buds were observed growing 
from the explant of S. lycopersicum on MS basal medium supplemented with $0.000003 \mathrm{~kg} / \mathrm{L}$ BAP alone. It was found that the combination of BAP with MS basal medium resulted in shoot and root initiation. The results have shown that growth in vermicompost medium has been significantly higher and faster as when compared with MS basal medium. Vermicompost was evaluated with different methods of extraction and this was used as a source of nutrients for tissue culture media for micropropagation of S. lycopersicum. Vermicompost media showed significantly higher growth rates of roots, nodes and leaves over MS media. This indicated the presence of certain biomolecules present in vermicompost that aid in the higher shoot and root induction, significantly leading to nodes and leaves formation from tomato seeds. Vermicompost contains certain growth promoters such as auxins, gibberellins and cytokinins that help in the initiation and promotion of the growth of shoots and roots (23). Vermicompost is rich in vitamins, minerals, enzymes and antibiotics providing a good balance in nutrients helping better growth rate and survival of the micropropagated plantlets for longer without requiring frequent subculturing as when compared to MS media. Vermicompost media has been shown to produce humic acid and fulvic acid which are known to have hormone-like activities and other bioactive compounds which help in better uptake of nutrients (24). Additionally, reduced rate of contamination was found in the vermicompost medium compared to MS medium due to the presence of coelomic fluid which has antimicrobial activity (25). The response of roots, leaves, shoots and nodes in both MS medium and chemicalfree vermicompost extract medium was compared statistically using Student's t-test. There were statistically significant differences between the mean values of growth rate of roots $(P=0.011)$ (Fig. 1$)$, leaves $(P=0.012)$ (Fig. 2 ) and nodes $(P<0.001)$ (Fig. 3 ) between the MS and vermicompost media. No statistically significant differences were seen between the two media for shoot induction ( $P>0.05$ ) (Fig. 4).

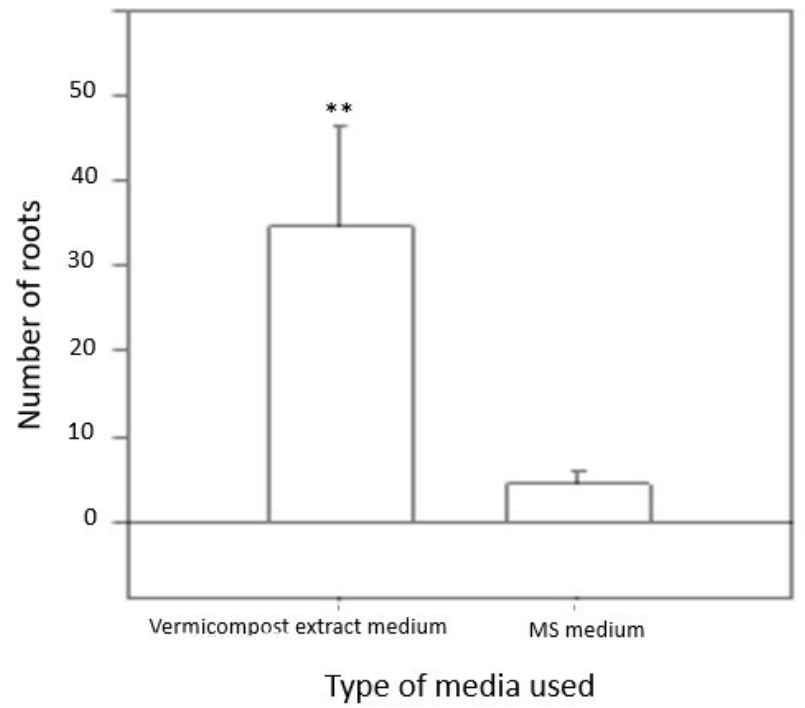

Fig. 1. Results of Student's T-test for the number of roots seen on the plantlets grown in vitro on MS media and vermicompost extract media ${ }^{\star \star}, \mathrm{P}<$ $0.05 ;{ }^{\star \star \star \star} \mathrm{P}<=0.005$; NS, not significant)

On the third day, we observed a $0.3 \mathrm{~cm}$ and $0.5 \mathrm{~cm}$ growth in MS and vermicompost media respectively. At end of the first week, we observed a 4 fold and 5 fold rise in shoot

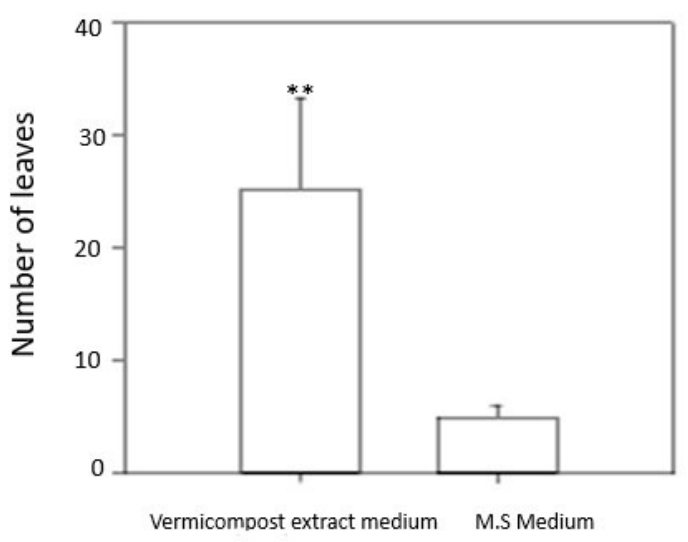

Types of media used

Fig. 2. Results of Student's T-test for the number of leaves seen on the plantlets grown in vitro on MS media and vermicompost extract media ( ${ }^{\star \star}, \mathrm{P}<0.05$; ${ }^{\star \star \star \star} \mathrm{P}<=0.005$; NS, not significant).

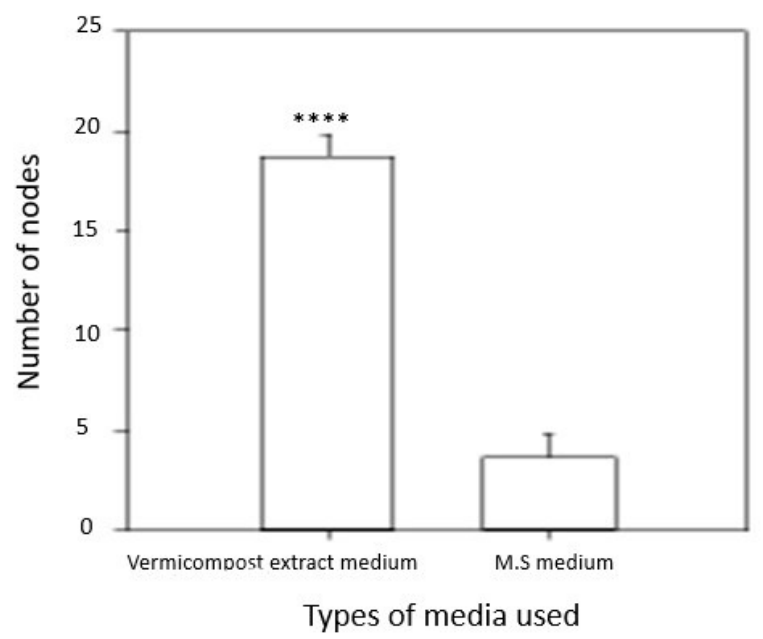

Fig. 3. Results of Student's T-test for the number of nodes seen on the plantlets grown in vitro on MS media and vermicompost extract media ( ${ }^{\star \star}, \mathrm{P}<0.05$;

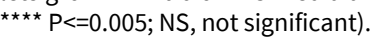

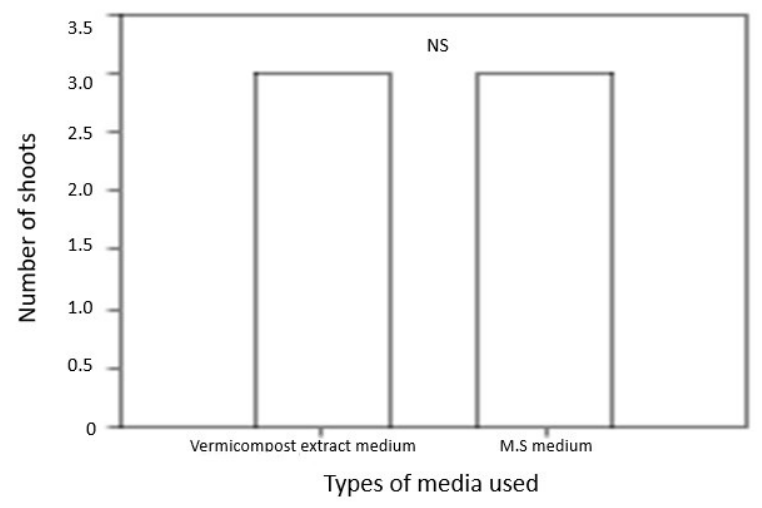

Fig. 4. Results of Student's T-test for the number of shoots seen on the plantlets grown in vitro on MS media and vermicompost extract media $\left({ }^{* \star}, \mathrm{P}<0.05\right.$; ${ }^{\star * \star \star} P<=0.005$; NS, not significant).

length in MS and vermicompost media respectively. After three weeks we found that the growth rates of tomatoes were $0.54 \mathrm{~cm}$ per day and $2.15 \mathrm{~cm}$ per day in MS and vermicompost media respectively (Fig. 5). Results recorded showed a difference in the growth rate of S. lycopersicum where we observed a faster growth rate with minimal contamination in vermicompost media compared to MS media (Figs. 6 and 7). Subsequent subculturing to reduce the contamination and to promote faster growth is not a necessary protocol when chemical-free vermicompost ex- 


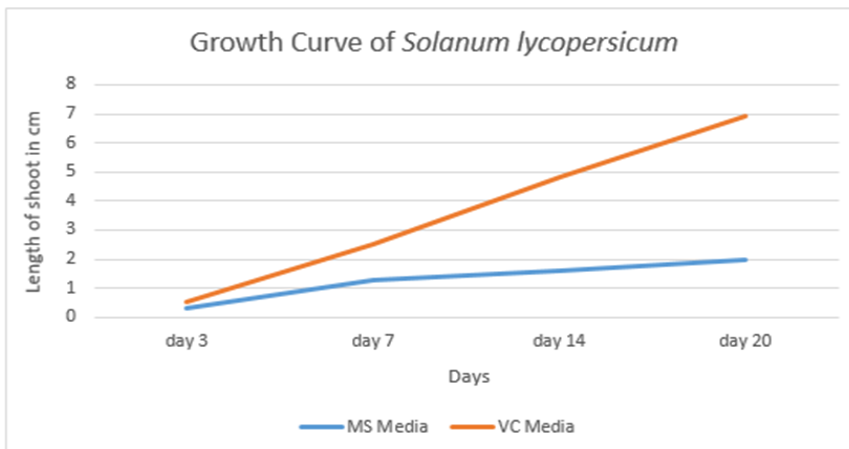

Fig. 5. Comparison of length of shoots in $\mathrm{cm}$ of S. lycopersicum on MS media and vermicompost (VC) media across 20 days.

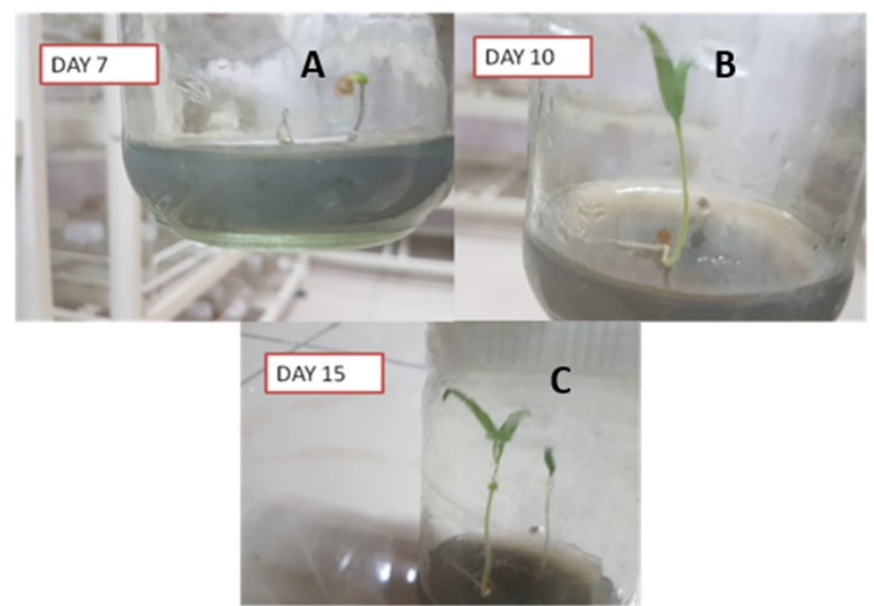

Fig. 6. Shoot induction from the cotyledonary explants of S. lycopersicum on vermicompost extract medium supplemented with coelomic fluid (organic media). A. Shoot induction on Day 7, B. Shoot induction on Day 10 and C. Shoot induction on Day 15.

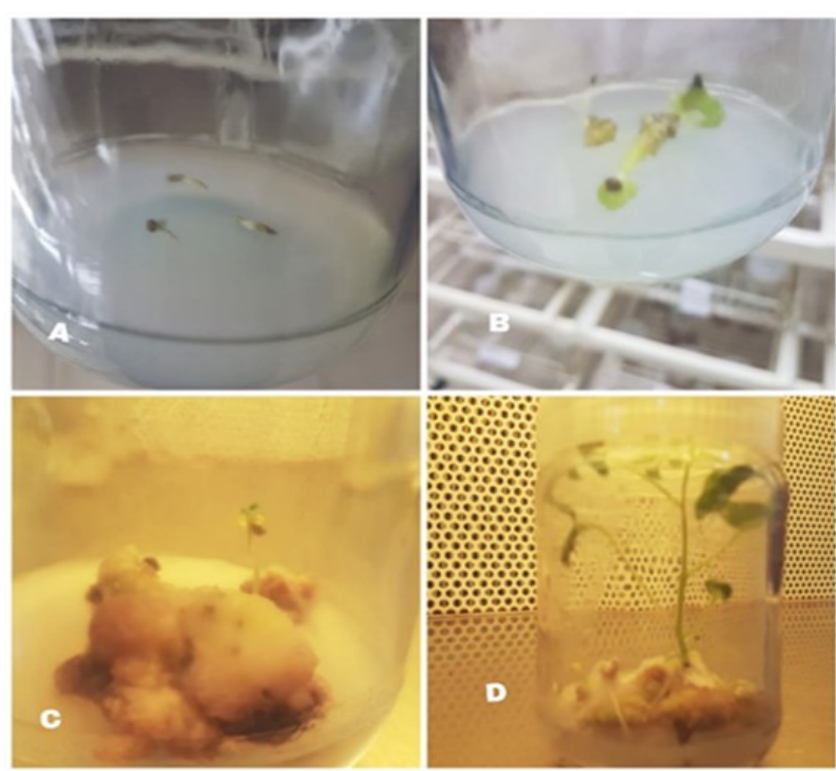

Fig. 7. Callus induction and micropropagation of S. lycopersicum on MS med um. A- Germination of seeds (day 15), B- Callus induction (day 20), C- Callus formation (day 30), D- Regeneration from callus (day 45).

tract media was used. However, timely subculturing is a compulsory protocol to be followed when MS medium was used for maintaining the cultures and the plantlets grown in MS medium were further subcultured for 5 days. Tissue cultured plantlets were primarily hardened using cocapeat and vermicompost in a 1:1 ratio at room temperature (25 ${ }^{\circ} \mathrm{C}$ ) and $72 \%$ humidity (Fig. 8).

For successful micropropagation, plant media com-

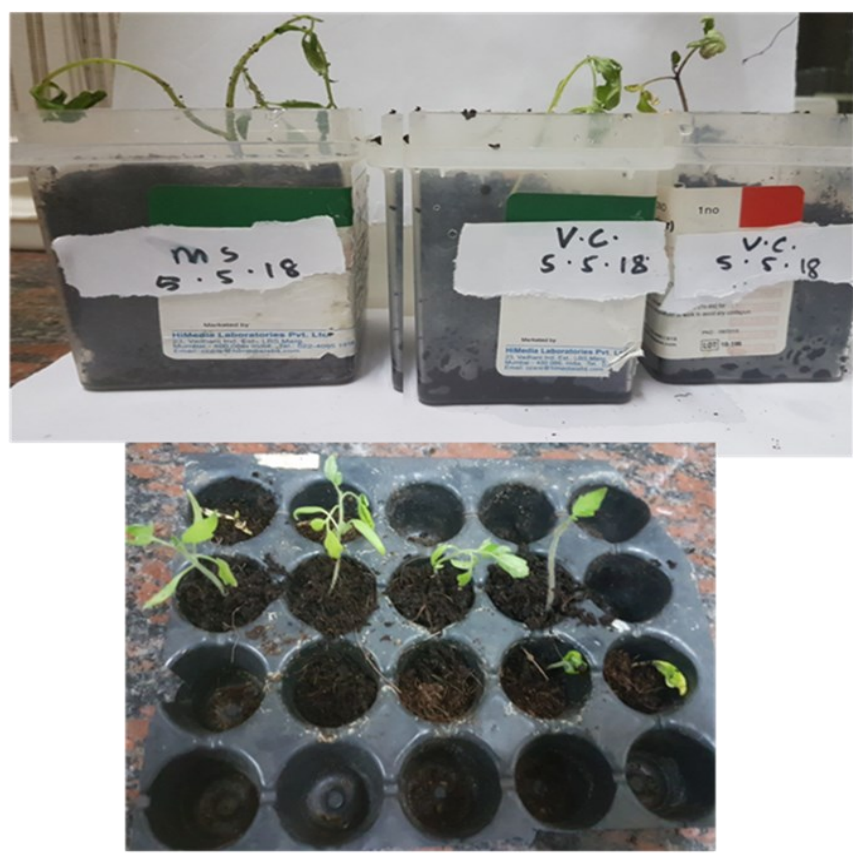

Fig. 8. Primary hardening of the micro-propagated plantlets developed on MS and vermicompost extract medium supplemented with earthworm coelomic fluid.

ponents and growth stimulators at required concentrations play a more significant role among other in vitro factors (26). Most of the researchers have relied on using a commercially available-expensive synthetic medium that uses various chemicals for the growth and maintenance of the explants for their micropropagation studies. On the contrary, our inexpensive protocol uses chemical-free organic components for micropropagation studies, which has led to $100 \%$ plant survival

\section{Conclusion}

Our research exposed the benefits of utilizing vermicompost media over MS media. Vermicompost has shown a tremendous positive effect on the growth and development of horticultural plants in field experiments. Using vermicompost in in vitro studies has helped to reduce the usage of chemicals and thereby decrease the detrimental consequences on the environment. Research has shown that humic and fulvic acids present in the vermicompost exhibit growth-promoting like activities that led to a faster growth rate. Additionally, repeated subculturing and contamination was minimized by using organic media. Future directions from this study will include the use of different concentrations and combinations of growth hormones along with different explants. Our study was done on a small scale and since vermicompost media is more economical, the same methodology can be applied for the large-scale production of tomato. Hence, chemical-free organic plant growth media using vermicompost extracts along with earthworm coelomic fluid can be an alternative to synthetic media for callus induction and micropropagation of economically important plants.

\section{Acknowledgements}

We authors thank the Management and Staff members of 
PES University for providing us the opportunity to work on the present research project and also for encouraging us to awaken the surroundings with this research about the Go Green Technology. .

\section{Authors contributions}

SK conceived the study. SK and ST participated in the design of the study. AS and SS prepared both the media and carried out all of the tissue culture experiments. SK, AS, and SS contributed towards the hardening of the explants. All four authors participated in data analysis. SK drafted the manuscript, after which AS and SS contributed significantly towards editing of the same. All four authors scrutinised and approved the final manuscript.

\section{Compliance with ethical standards}

Conflict of interest: The authors declare no conflict of interest

Ethical issues: None.

\section{References}

1. Bhatia P, Ashwath N, Senaratna T, Midmore D. Tissue culture studies of tomato (Lycopersicon esculentum). Plant Cell Tissue and Organ Culture. 2004;78(1):1-21. https://doi.org/10.1023/ B:TICU.0000020430.08558.6e.

2. Shukla P, Bajpai K, Shalini T, Kumar S, Gautam, Kumar G. A review on the taxonomy, ethnobotany, chemistry and pharmacology of Solanum lycopersicum Linn. International Journal of Chemistry and Pharmaceutical Sciences (IJCPS). 2013; 1(8):521-27.

3. Hobson GE, Davies JN. The Tomato. In: Hulme AC, editor. The biochemistry of fruits and their products. Vol. 2. New York: Academic Press; 1971. p. 437-82.

4. Gerster $\mathrm{H}$. The potential role of lycopene for human health. Journal of the American College of Nutrition. 1997;16(2):109-26. https://doi.org/10.1080/07315724.1997.10718661.

5. Rao A, Agarwal S. Role of antioxidant lycopene in cancer and heart disease. Journal of the American College of Nutrition. 2000; 19(5):563-69 https://doi.org/10.1080/07315724.2000.10718953.

6. Hobson GE, Grierson D. Tomato. In: Seymour GB, Taylor JE, Tucker GA, editors. Biochemistry of Fruit Ripening. Dordrecht: Springer; 1993. p. 405-42. https://doi.org/10.1007/978-94-011-15841_14.

7. Singh A. Micropropagation of Plants. In: Bahadur B, Venkat Rajam M, Sahijram L, Krishnamurthy K, editors. Plant Biology and Biotechnology. New Delhi: Springer; 2015. p. 329-46. https://doi.org/10.1007/978-81-322-2283-5_16.

8. Izadpanah M, Khosh-Khui M. Comparisons of in vitro propagation of tomato cultivars. Iran Agricultural Research. 1992;8(1):37-47. https://doi.org/10.22099/ IAR.1989.4476.

9. Gubis J, Lajchova Z, Farago J, Jurekova Z. Effect of genotype and explant type on shoot regeneration in tomato (Lycopersicon esculentum Mill.) in vitro. Czech Journal of Genetics and Plant Breeding. 2003;39:9-14.

10. Ishag S, Osman MG, Khalafalla MM. Effects of growth regulators and genotype on shoot regeneration in tomato (Lycopresicon esculentum cv. Omdurman). International Journal of Sustainable Crop Production. 2009;4(6):7-13.
11. Lima JE, Benedito VA, Figueira A. Callus, shoot and hairy root formation in vitro as affected by the sensitivity to auxin and ethylene in tomato mutants. Plant Cell Reports. 2009;28:1169-77. https://doi.org/10.1007/s00299-009-0718-y.

12. Chaudry A, Abbas S, Yasmin A, Rashid H, Ahmed H, Anjum MA. Tissue culture studies in tomato (Lycopesricon esculentum) var. Moneymaker. Pakistan Journal of Botany. 2010;1:155-63.

13. Gubis J, Lajchová Z, Faragó J, Jureková Z. Effect of growth regulators on shoot induction and plant regeneration in tomato (Lycopersicon esculentum Mill.). Biologia Bratislava. 2010;59 (3):405-08.

14. Gray WM. Hormonal regulation of plant growth and development. PLOS Biology. 2004;2(9):311. https://doi.org/10.1371/ journal.pbio.0020311.

15. Mamidala P, Nanna RS. Effect of genotype, explant source and medium on in vitro regeneration of tomato. International Journal of Genetics and Molecular Biology. 2011;3(3):45-50.

16. Kale RD, Bano K, Srinivasa MN, Nagaraj DJ. Influence of wormicast on the growth and mycorrhizal colonization of two ornamental plants. South Indian Horticulture. 1987;35:433-37.

17. Edwards CA, Burrows I. The potential of earthworm compost as plant growth media. In: Edward CA, Neuhauser EF, editors. Earthworms in Waste and Environmental Management. The Hague: SPB Academic Publishing; 1987. p. 21-32.

18. Suhane RK. Vermicompost. Publication of Rajendra Agriculture University, Pusa. 2007; 88.

19. Roch P, Lassegues M, Valembois P. Antibacterial activity of Eisenia fetida andrei coelomic fluid: III--Relationship within the polymorphic hemolysins. Developmental and Computational Immunology. 1991;15(1-2):27-32. https://doi.org/10.1016/0145305x(91)90044-y.

20. Azizan MNA, RISDA. The effect of BAP and NAA treatment on micropropagation of Cucumis sativus L. International Journal of Science and Research. 2017;6(11):170-76. https:// doi.org/10.21275/ART20177887.

21. Otroshy M, Khalili Z, Ebrahimi MA, Nekoui MK, Moradi K. Effect of growth regulators and explant on plant regeneration of Solanum lycopersicum L. var. cerasiforme. Russian Agricultural Sciences. 2013;39(3):226-35. https://doi.org/10.3103/S1068367413030178

22. Harish MC, Rajeevkumar S, Sathishkumar R. Efficient in vitro callus induction and regeneration of different tomato cultivars of India. Asian Journal of Biotechnology. 2010;2(3):178-84. https:// doi.org/10.3923/ajbkr.2010.178.184

23. Lamichhane J, Chaulagain A, Dhruva P, Gauchan. Vermicompost and its role in plant growth promotion. International Journal of Research. 2017;4(8):849-64.

24. Kashyap, S, Kapoor N, Kale R. Effect of vermicompost extracts on the in vitro micropropagation of Bacopa monnieri. International Journal of Green Pharmacy. 2015;9(1):63-68. https:// doi.org/10.4103/0973-8258.150930.

25. Kashyap S, Kale RD. Callus induction and tissue differentiation of Tinospora cordifolia on using vermicompost and its extracts along with coelomic fluid as tissue culture media. Horizon Journal of Microbiology and Biotechnology Research. 2015;1:1-7.

26. Ružić DJV, Vujovic TI. The effects of cytokinin types and their concentration on in vitro multiplication of sweet cherry cv. Lapins (Prunus avium L.). Horticultural Science. 2008;35(1):12-21.

27. Murashige T, Skoog F. A revised medium for rapid growth and bioassay with tobacco tissue culture. Physiology Plant. 1962;215:473-95. 